\title{
Geothermal reservoir prediction using electrical resis- tivity maps: A case study of Lili Sepporaki Indonesia
}

\author{
Denis Mutebi ${ }^{1 *}$, Andi Agus Nur ${ }^{2}$, Agus Didit Haryanto ${ }^{3}$, Joni Wiwid ${ }^{4}$, Michael Kazinda ${ }^{5}$ \\ 1, 2, 3 Faculty of Geological Engineering, Universitas Padjadjaran, Jalan Raya Bandung-Sumedang, Indonesia \\ ${ }^{4}$ Department of Geophysics, Centre for Minerals, Coal and Geothermal Resources (PSDMBP), Soekarno-Hatta, \\ Bandung, Indonesia \\ ${ }^{5}$ WE Consult, Plot 41 Lake Drive, Luzira Kampala, Uganda
}

\author{
Keywords \\ Magnetotellurics (MT) \\ Hydrothermally \\ Alteration \\ Weathered \\ Two-dimensional
}

Received: 11 May 2019

Accepted: 13 July 2019

Published: 31 October 2019

\begin{abstract}
The objective of this study is to predict the location of the geothermal reservoir through interpretation of Magnetotelluric depth-resistivity maps, with reference to Lili-Sepporaki geothermal area. Lili-Sepporaki is a nonmagmatic prospect located in Polewali Mandar, Western Sulawesi-Indonesia. The study area is dominated by andesitic to trachytic to trachytic tertiary volcanic products. The only thermal manifestations in the area are the hot springs and rock alterations. Previous geochemical studies found out the hot spring water has temperature of $98^{\circ} \mathrm{C}$ and the reservoir temperature of $190^{\circ} \mathrm{C}$. A big portion of the surface rocks are weathered and hydrothermally altered owing to findings from magnetic and Bouguer gravity surveys. This research utilized two-dimensional magnetotellurics data to locate resistivity anomalies in the subsurface. MT data was processed using SSMT2000 and MTEditor software programs while WinGLink software was used in the interpretation of the data. Four resistivity maps were obtained, each corresponding to one of the depths: $500 \mathrm{~m} ; 1000 \mathrm{~m} ; 1500 \mathrm{~m}$; and $2000 \mathrm{~m}$. There is a general sharp reduction in resistivity as opposed to the conventional resistivity of fresh igneous rocks. Analysis shows that the reservoir appears between depths of $1000 \mathrm{~m}$ and 2000 in different parts of the survey area, with prospect boundaries located in the South, South West and South East. A three-dimensional MT data analysis and exploration drilling are recommendable in order to get a detailed geothermal model.
\end{abstract}

(C) 2019 The Author(s). Published by TAF Publishing.

\section{INTRODUCTION}

Energy is a very vital factor for human survival. However, many energy resources are a source of environmental pollutants, such as Carbon dioxide, and their associated hazards $[1,2]$. Geothermal is a clean and renewable energy source that can serve to alleviate the problem of Pollution. Geothermal energy, can not only be used for electricity generation, but also in many human activities that require heating such as Agriculture [3, 4].

Indonesia occupies a big part of the ring of the "Ring of fire", and therefore has a huge geothermal potential due to a large chain of volcanoes spread along the several islands that make it up [5, 6]. Despite the big potential, Indonesia still heavily depends on non-renewable energy sources such as Hydrocarbons which are associated with production of pollutants [7]. This fact calls for massive research and investment in the geothermal sector.

Lili Sepporaki is one of the many geothermal prospects found in Polewali Mandar District, Western SulawesiIndonesia. Sulawesi Island is located at the site of interaction of 3 tectonic plates namely: Indo-Australia; Eurasia; and Pacific; and this makes Sulawesi so active tectonically $[8,9]$. Tectonic activity is a very good aspect in geothermal exploration, especially in relation to permeability and fluid pathways. The only surface manifestations in the area are the hot springs with average temperature of $98^{\circ} \mathrm{C}$ and rock alterations $[10,11]$. Heat associated with plutonism is most likely to be the heat source for the geothermal system

\footnotetext{
${ }^{*}$ Corresponding author: Denis Mutebi

†email: denis2003mutebi@gmail.com
} 
of Lilli-Sepporaki area [12].

Electrical resistivity techniques such as MT are deployed in several fields around the world to aid in location and delineation of the geothermal reservoirs at depth $[13,14]$. Rocks are electrical conductors in nature owing to the fact that they possess conducting particles such as ions and electrons. Highly resistive rocks such as igneous and metamorphic, tend to have drastic reductions in resistivities when they exist in geothermal conditions. The MT techniques always target such areas with resistivity anomalies, as they can give information about the extent of the geothermal field and the characteristics of the geothermal system of an area under investigation [15].

The objective of this research is to predict the location and delineation of the reservoir of Lili-Sepporaki geothermal prospect through analysis of depth resistivity maps obtained from MT data processing.

\section{LITERATURE REVIEW}

\section{A. Geology}

Lili Sepporaki prospect lies on a zone of depression which is due to tectonic activity that occurred during Oligocene. According to [16], this area is dominated by andesitic to trachytic volcanic rocks, which are tertiary volcanic products. These rocks are said to have undergone intensive fracturing thus responsible for permeability of the geothermal system. Tectonic activity that occurred in the Miocenepliocene, is responsible for the formation of North WestSouth East (NW-SE) trending faults that allegedly provide geothermal fluids paths ways to the surface. According to [12], Lili Sepporaki area consists of 12 stratigraphic units: The most dominant units at the surface are the Insperable volcanics (Tvt), Buttu Dambu andesitic lava (Tld), Porphyry Andesite (Tp) and Walimbong volcanics (Tvw). Tvt is silicified at one point, argillic at another point and made of andesitic to basaltic lava; Tld is a lava dome composed of trachytic andesite; Tp is composed of porphyritic andesite lava which is partially crystallised, fractured and weathered, and some small quantities of Pyrite minerals. Tvw is made up of andesitic lava which has experienced weathering, fracturing and chlorination in some parts [12]. According to the geologic model of the area, Tvw and Tp extend to a depth of more $2000 \mathrm{~m}$ in some parts of the survey area [12].

\section{B. Geochemistry}

According to [17], Lili Sepporaki area has two hot springs and analysis of $\mathrm{Cl}-\mathrm{SO}_{4}-\mathrm{HCO}_{3}$ diagram shows that they both have chloride water chemistry, indicating that the water comes from the reservoir. The waters also have a neutral
$\mathrm{pH}$. The Na-K-Mg diagram provides that both hot springs are in the partial equilibrium zone indicating that that hot fluid interacted with the contacted subsurface rocks as well as mixing with surface meteoric water. The Cl-Li-B diagram also confirms the former. The Na-K geothermometer indicates a reservoir temperature of $190^{\circ} \mathrm{C}$ [16].

\section{Geophysics}

The magnetic anomaly survey shows the distribution of sharp low magnetic anomalies in the West, Centre, North East (NE), and South East (SE) [17]-this is interpreted as hydrothermal alteration of volcanic rocks associated with hot areas. The residual Bouguer anomaly survey shows low anomalies in the North West (NW), Centre, South and East of the survey area [17]- and this is a reflection of weathered and hydrothermally altered rock formations.

\section{Electrical Conductivity of Rocks}

The conducting particles in rocks are the ions, electron and electron holes [18]. Increase in porosity, salinity and amount of conducting minerals, raises the ionic conductivity of rocks [19]. Hydrothermal alteration of rocks into clay reduces their resistivity by increasing their bulk conductivity $[13,20,21]$. The presence of conductive fluids in a rock raise the rock bulk conductivity [22]. Increase in temperature raises the solubility of ionic compounds. Compaction and precipitation reduces the conductivity of a fluid saturated rock by reducing the connectivity of pore spaces, thereby favouring resistivity $[18,22]$.

According to [23], metamorphic and igneous rocks have resistivity values of $1000 \mathrm{Ohm}-\mathrm{m}$ or more in their natural state. Weathered or hydrothermally altered igneous rocks have their resistivities lowered to less than $500 \mathrm{Ohm}-\mathrm{m}$. Clay minerals have resistivity values less than $100 \mathrm{Ohm}-\mathrm{m}$ [24].

\section{METHODOLOGY}

MT data was collected by PSDMBP in 2011 and data for 22 MT stations was processed and interpreted in this survey.

\section{A. Theory of MT Technique}

MT is a passive technique that depends on the natural variations in earth's magnetic field as a power source for induction of Electromagnetic (EM) field in the earth. This technique measures the variation of Electric (E) and Magnetic (H) fields in orthogonal directions at the surface of the earth [25]. 


\section{B. Maxwell's Equation}

These equations describe the behavior of EM fields at any frequency with in the conductor $[18,25,26]$. In other words, the measured E field and the corresponding induced $\mathrm{H}$ fields in the earth are generated according to the chain of equations (Equation 1).

$$
\nabla x E=-\frac{\partial B}{\partial t} ; \nabla X H=J_{f}+\frac{\partial D}{\partial t} ; \nabla \cdot B==0 ; \nabla \cdot D=\eta_{f}
$$

Where: $E=$ Electric field $\left(\mathrm{Vm}^{-1}\right)$

$B=$ Magnetic induction $(T)$

$H=$ Magnetic intensity $\left(\mathrm{Am}^{-1}\right)$

$D=$ Electric displacement $\left(\mathrm{Cm}^{-2}\right)$

$J_{f}=$ Electric current density owing to free charges $\left(\mathrm{Am}^{-2}\right)$

$\eta_{f}=$ Electric charge density owing to free charges $\left(\mathrm{Cm}^{-3}\right)$.

\section{Skin Depth}

This is also called the penetration depth, $P(T)$, it tells us how deep the EM waves penetrate into the earth and thus able to study the conductive properties of the subsurface at depth. The skin depth depends on the resistivity $\left(\rho_{a}\right)$ of the penetrated rock formations and the time $(T)$ for which the MT sounding is carried per cycle. The skin depth relation is thus described in the Equation 2.

$$
P(T) \approx 500 \sqrt{T \rho_{a}}
$$

\section{Apparent Resistivity and SSMT2000 Software Pro- gram}

SSMT2000 program integrates the measured E and H field data into complex algorithms and the output of which is apparent resistivity data, displayed by MTEditor software program. Impedance $(Z)$ compares the measured $E$ and $H$ values in orthogonal directions as described by the Equation 3 .

$$
\left(\begin{array}{c}
E_{x} \\
E_{y}
\end{array}\right)=\left(\begin{array}{cc}
Z_{x x} & Z_{x y} \\
Z_{y x} & Z_{y y}
\end{array}\right)\left(\begin{array}{c}
H_{x} / \mu_{0} \\
H_{y} / \mu_{0}
\end{array}\right)
$$

Where $E_{x}$ and $E_{y}$ are the horizontal components of the Electric field; $H_{x}$ and $H_{y}$ are the horizontal components of the magnetic field; $Z_{x x}, Z_{x y}, Z_{y x}$ and $Z_{y y}$ are components of impedance; $\mu_{0}$ is the magnetic permeability of free Space. Apparent resistivity, $\rho_{a}$, refers to the average resistivity of an equivalent uniform half space of the earth [25]. Each component of impedance has both magnitude and phase $(\phi)$. According to [26], apparent resistivity is described in Equation 4 and the phase of the impedance in Equation 5.

$$
\begin{gathered}
\rho_{a}=0.2 \tau|Z|^{2}=0.2 T \frac{|E|^{2}}{|H|^{2}} \\
\phi=\tan ^{-1} \frac{\left(\operatorname{imag}\left[\frac{E_{x}}{H_{x}}\right]\right)}{\left(\operatorname{Re} a l\left[\frac{E_{x}}{H}\right]\right)}
\end{gathered}
$$

Where

$E=$ The horizontal electric field in $\mathrm{mv} / \mathrm{km}$

$H=$ The orthogonal horizontal magnetic field in gamma

$\rho_{a}$ is the apparent resistivity in $\Omega-m$ and $T$ is the period in seconds.

\section{E. MT Editor Software Program}

MT Editor displays the resistivity and phase curves with individual crosspowers. This programme also eliminates the crosspowers that were affected by noise by editing one frequency at a time. The edited cross-power power data are then converted into industry-standard EDI files format [24].

\section{F. WinGLink Software Program}

This software was used for editing MT sounding data, TwoDimension (2D) inversion and producing depth resistivity maps. MT sounding editing involves static shifting and data smoothing; 2D Inversion is concerned with prediction of the real valued model parameters of the earth's resistivity from real valued MT field experiment data; resistivity maps are produced from the resulting $2 \mathrm{D}$ resistivity models.

\section{A. Results and Analysis}

A total of 4 depth maps were made from the best five 2D resistivity models. Each map is made up of processed data from 22 MT stations. Each map represents a depth in the subsurface that is to say; $500 \mathrm{~m}, 1000 \mathrm{~m}, 1500 \mathrm{~m}$, and 2000 $\mathrm{m}$. The resistivities on the maps are classified into 4 groups, that is: low resistivity ( $<50 \mathrm{Ohm}-\mathrm{m})$, medium resistivity (50-100 Ohm-m), high resistivity (100- 250 Ohm-m) and very high resistivity (> $250 \mathrm{Ohm}-\mathrm{m}$ ).

1) Resistivity map at depth of $500 \mathrm{~m}$ : Low resistivity dominates the more than half of the study area especially in the North, NW, SE and Eastern parts (Figure 1). This is evidence of weathering where the near-surface volcanic rocks are changed into the conductive clay rich rocks. This is the inseparable volcanic rock formation according to geology. Clay rich rocks have a tendency of adsorbing conductive ions on their surfaces, hence an increase in conductivity. Medium resistivity runs from the west, through the centre into the SE and reflects the hydrothermally altered 
rocks. The zone between the medium and high resistivity is marked by an increase in contour density as evident in the southern section of the survey area. The increase in contour is probably due to the presence of a structure in the south- ern section with a NW-SE orientation (Figure 5). The very high resistivity seen in the south is probably response from andesite lava rock possibly from Tvt and Tp formations- its contours open to the south.

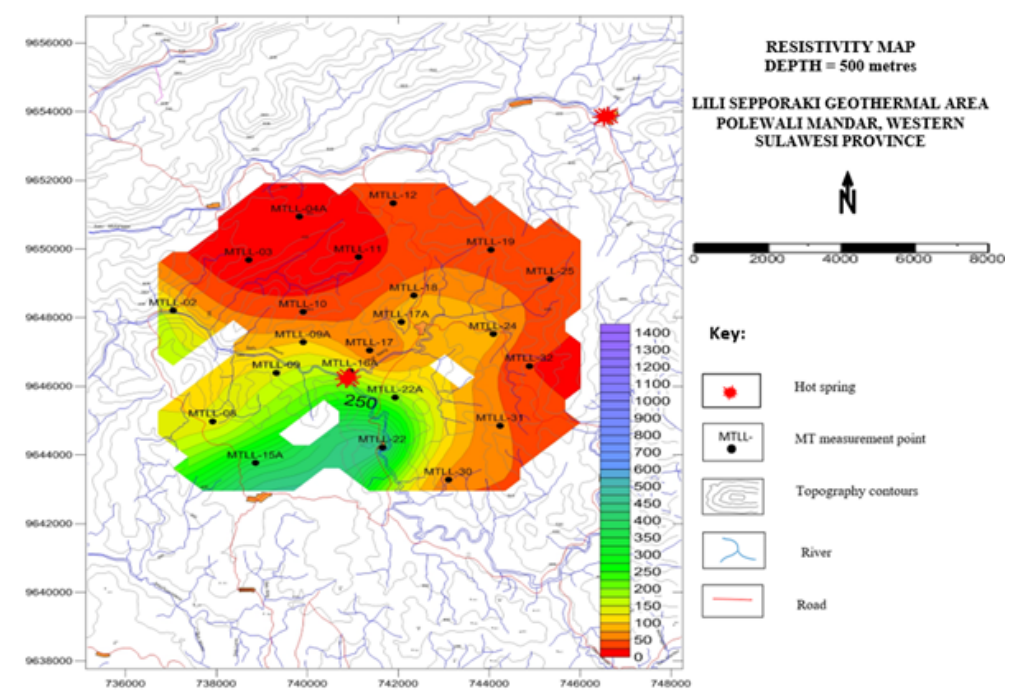

Fig. 1. Resistivity map at a depth of $500 \mathrm{~m}$ with colour contrast representing resistivity in Ohm-m

2) Resistivity at a depth of $1000 \mathrm{~m}$ : The low resistivity anomaly shrinks and its now only evident in the North and East-its contours open to the North in the Northern section (Figure 2). The medium resistivity area spreads more to the North and NW- this is due to the fact there are more partially hydrothermally altered rocks at that depth than the previous map. High resistivity appears for the first time in the centre around station MTLL-17A towards the NE. This is because of the transition from the cap rock to the rock formation filled with hot fluid- allegedly the reservoir rock (Figure 5). A very high resistivity anomaly (> $250 \mathrm{Ohm}-$ m) appears in the South as in the previous map but with a higher value of resistivity- this is probably a typical response from andesitic rocks. The contour density increases during the transition zone from medium to high resistivity in the South- the structure allegedly available in southern section penetrates up to this depth.

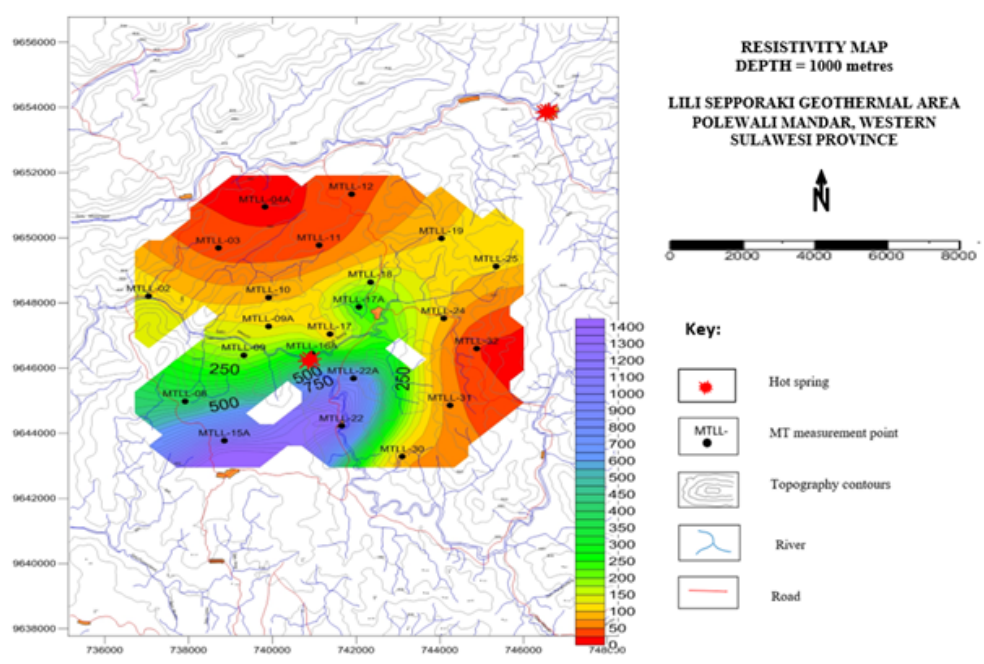

Fig. 2. Resistivity map at a depth of $1000 \mathrm{~m}$ with colour contrast representing resistivity in $\mathrm{Ohm}-\mathrm{m}$ 
3) Resistivity at a depth of $1500 \mathrm{~m}$ : As seen in Figure 3, the low resistivity disappears in the North and it is only persistent in the SE- the latter observation can be interpreted as a structure that forms the reservoir or prospect boundary in the SE. The medium resistivity dominates the North-it acts as the cap rock for the reservoir in this geothermal system. The medium resistivity contours in this region are open to the North. The high resistivity spreads even to the NW of the survey area and has almost the same distribution in the centre through the NE but with a higher value of resistivitythis is interpreted as the reservoir at this depth (Figure 5). The very high resistivity in the south has the same distribution as in the previous map, with an open contour.

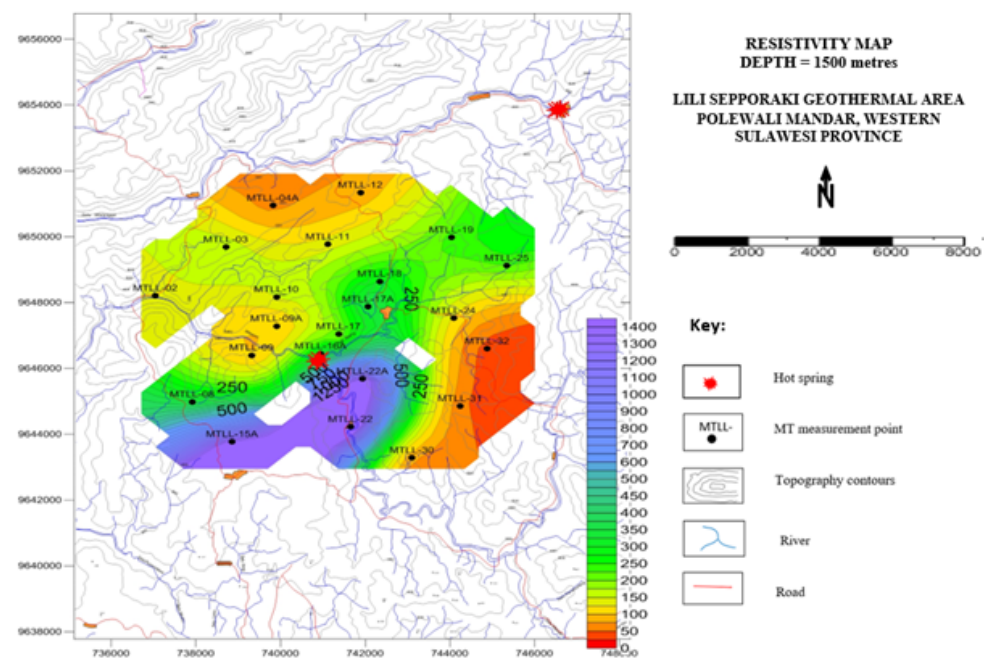

Fig. 3. Resistivity map at a depth of $1500 \mathrm{~m}$ with colour contrast signifying resistivity in Ohm-m

4) Resistivity at a depth of $2000 \mathrm{~m}$ : The low resistivity anomaly that was present on both the previous map and this map in the SE probably forms the reservoir boundary and thus prospect boundary in this part of the survey area. Also, the low resistivity anomaly in the SW can also be referred to as boundary structure for the reservoir (Figure 4 and Fig- ure 5). The reservoir rock that was present in the previous map in the NE and NW changes into a very high resistive rock, most likely a metamorphic rock- the contours in these sections are open. The high resistive rock or the reservoir is still evident in the centre and North at this depth.

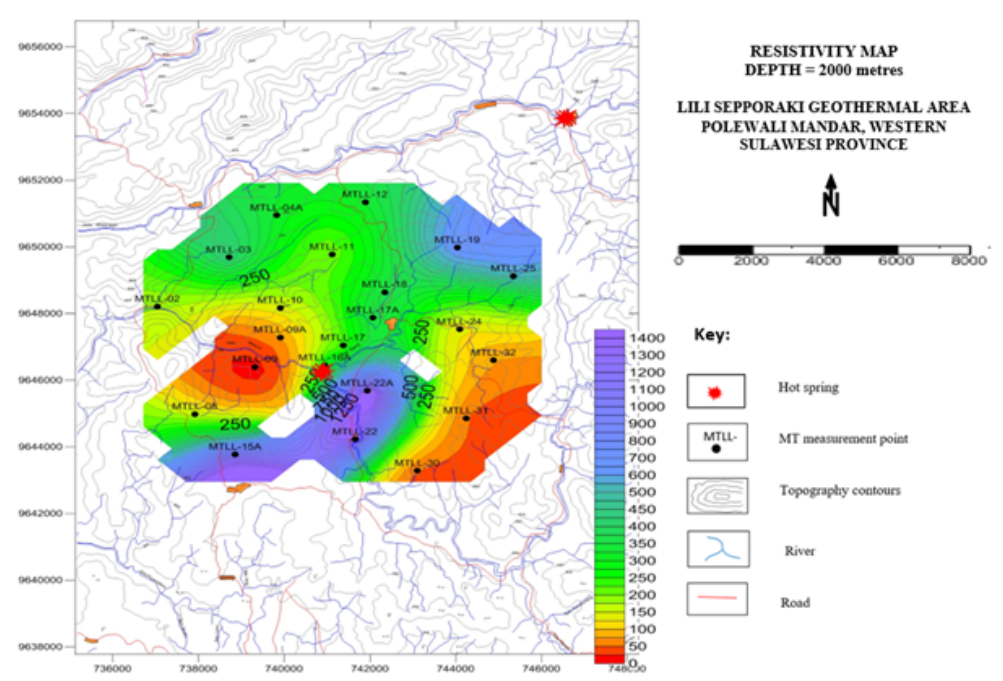

Fig. 4. Resistivity map at a depth of $2000 \mathrm{~m}$ with colour contrast signifying resistivity in Ohm-m 
All the resistivity maps at different levels are represented below on a typical layered earth model (Figure 5). The simulated reservoir delineation at each elevation is marked, plus the boundary of the reservoir or prospect in different regions of the survey area.

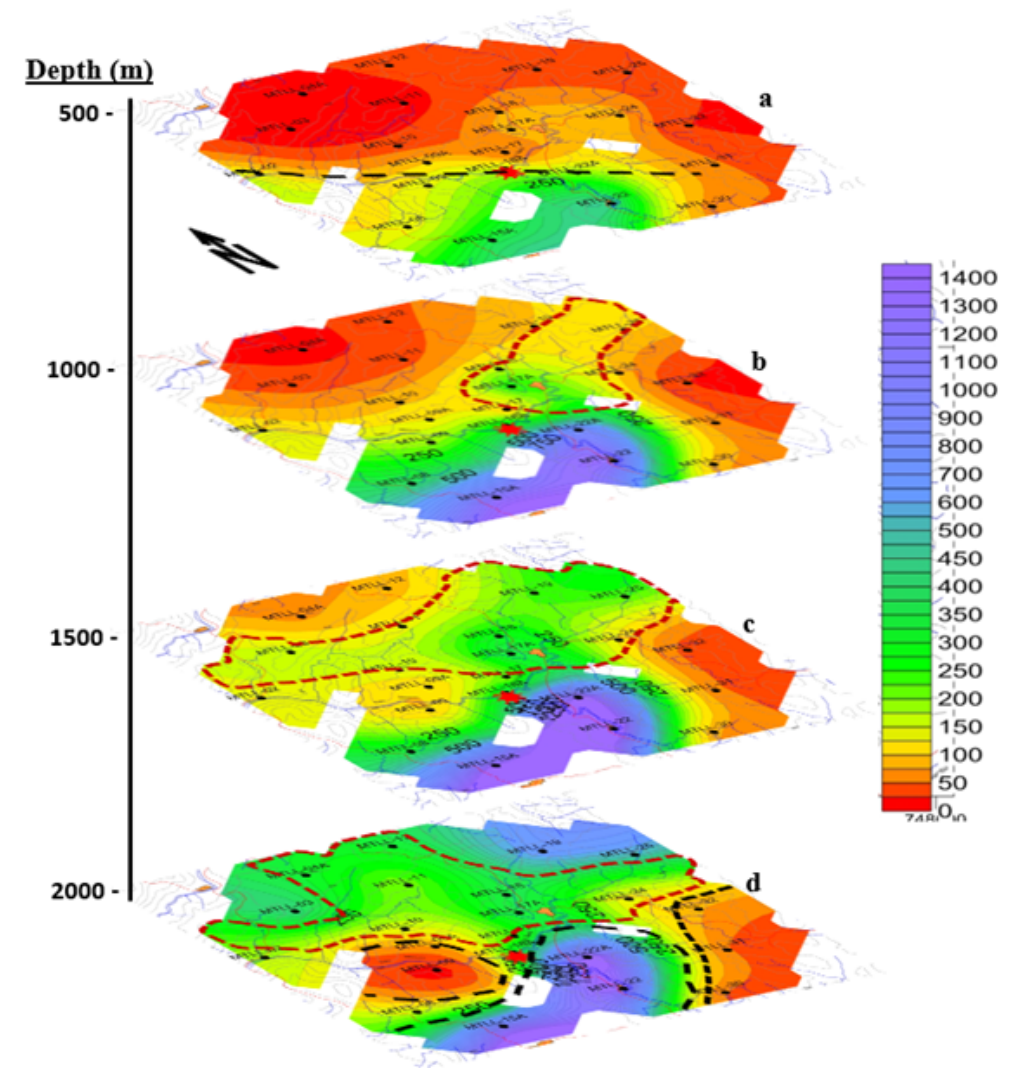

Fig. 5. Earth model with Resistivity layers at different depths: $a=500 \mathrm{~m} ; \mathrm{b}$ $=1000 \mathrm{~m} ; \mathrm{c}=1500 \mathrm{~m} ; \mathrm{d}=2000 \mathrm{~m}$. Reservoir is enclosed in red dotted lines while black dotted represent structures that act as reservoir boundaries.

\section{B. Discussion}

1) Reduced resistivity between $1000 \mathrm{~m}$ and $2000 \mathrm{~m}$ : The rock formations Tp and Tvw are found at depth in the survey area and these formations are highly fractured and weathered according to [12]. The fractures provide spaces and connections for fluid storage and accumulation while the weathering products have the ability to adsorb conducting species (ions) at their surfaces. The reduced resistivity at a depth of $1000 \mathrm{~m}$ or deeper as seen on the respective resistivity maps (Figure 5), confirms that the respective formations contain either a conductive fluid or clay, responsible for the reduction in resistivity. Geochemical studies found out that the geothermal fluid is rich in chloride ions [10], which are electrically conductive in nature. Electrical resistivity of rocks at depth is lowered due to the presence of a saline fluid at depth [19], however the resistivity at these depths does not reduce below $100 \mathrm{Ohm}-\mathrm{m}$ as would be for clay-rich rocks. At this point, the existence of clay-rich rocks as a factor for resistivity decrease at such depths, is negated. Therefore, the delineated areas (red-dots) on the maps with reduced resistivity undoubtedly correspond to fluid-filled fractured formations.

2) Resistivity anomaly at 500m depth: Formations such as Tp, Tvw and Tvt are exposed at the surface and near surface, and the geological model of the area, provides that these formations are argillic, propylitic and silicified [12]. All the above attributes are connected with hydrothermal alteration of rocks, resulting into reduction of permeability. The latter would rule out the fact such near-surface formations contain a fluid, and so it's only weathering products that can account for a low resistivity anomaly in this case. Clay-rich alteration products are electrically conductive and thus have an anomalous negative impact on the bulk resistivity on of rocks that host them $[13,20,21]$. Additionally, 
clay-rich rocks have resistivity values less than $100 \mathrm{Ohm}$ $\mathrm{m}$ [22]. Magnetic and gravity survey results also show that much of the surface rocks are weathered [17]. Thus low resistivity formations at a depth of $500 \mathrm{~m}$ or shallower are undoubtedly clay-rich rocks, part of which can serve as cap rocks of the geothermal system of Lili-Sepporaki.

\section{CONCLUSION, LIMITATIONS AND RECOMMENDATIONS}

\section{A. Conclusion}

There is a general reduction in electrical resistivity as opposed to the conventional values for typical igneous rocks. The reservoir starts to appear at a depth of $1000 \mathrm{~m}$ downwards. Parts of the Walimbong and Porphyry andesite formations serve as the reservoir. According to geology, Walimbong and Porphyry andesite formations are fractured and extend up to more than $2000 \mathrm{~m}$ deep. The rock formations above the reservoir have even lower resistivities and so they act as cap rocks. Cap rocks in geothermal systems are usually near-surface impermeable and conductive rocks that are formed as a result of hydrothermal alteration of parent rocks, in a geothermal environment. According to geology, Walimbong and inseparable volcanics are weathered or hydrothermal-altered rock formations extending from the surface to the near-surface. Additionally, magnetic and residual gravity surveys point to the existence of weathered rocks at the surface. Geochemical surveys also provide for the interaction of hot fluids from the reservoir, with the rocks they pass through to the surface, thus evidence for rock alteration. Structures that serve as boundaries for the reservoir exist in the South, SE and SW of the prospect area. The structure in the south with a NW-SE orientation is allegedly a fault and cuts through the Sepporaki hot spring according to the geology.

\section{B. Limitations and Recommendations}

The detailed available literature for magnetic and gravity surveys was not accessible. Therefore, I did not as exhaustively as I would wish, relate my analysis of findings to the existing literature of the area. Also, there was not enough data points for analysis and this affected the quality of resolution of the prospect.

Another MT survey with more survey stations than the previous survey, should be carried out in the area. The new survey should basically target a three-dimensional MT data analysis. A successful analysis should be followed by exploration drillings in order to get a detailed geothermal model and define potential drilling targets.

\section{ACKNOWLEDGEMENT}

The department of geophysics of the Centre for minerals, Coal and Geothermal resources (PSDMBP)- Indonesia, is highly appreciated for providing both the laboratory facility and supervision during data processing.

\section{REFERENCES}

[1] M. Abdolalipouradl, S. Khalilarya, and S. Jafarmadar, "Energy and exergy analysis of a new power, heating, oxygen and hydrogen cogeneration cycle based on the sabalan geothermal wells," International Journal of Engineering, vol. 32, no. 3, pp. 445-450, 2019. doi: https://doi.org/10.5829/ije.2019.32.03c.13

[2] H. Akamine, M. Mitsuhara, and M. Nishida, "Developments of coal-fired power plants: Microscopy study of Fe-Ni based heat-resistant alloy for efficiency improvement," Evergreen: Joint Journal of Novel Carbon Resource Sciences \& Green Asia Strategy, vol. 3, no. 2, pp. 45-53, 2016. doi: https://doi.org/10.5109/1800871

[3] J. W. Lund and T. Boyd, "Geothermal energy uses: A quarterly progress and development report on the direct utilization of geothermal resources," Geo-Heat Center Quarterly Bulletin, vol. 28, no. 2, pp. 34-50, 2007.

[4] M. Yucel and M. Halis, "Iso 50001 based integrated energy management system and organization performance,"Journal of Advances in Technology and Engineering Research, vol. 2, no. 2, pp. 52-58, 2016. doi: https://doi.org/10.20474/ jater-2.2.5

[5] B. T. Prasetyo, M. Oktaufik, S. Himawan et al., "Design, construction and preliminary test operation of BPPT-3MW condensing turbine geothermal power plant," Evergreen, vol. 6, no. 2, pp. 162-167, 2019. doi: https://doi.org/10.5109/ 2321012

[6] A. Fauzi, S. Bahri, and H. Akuanbatin, "Geothermal development in Indonesia: An overview of industry status and future growth," in Proceedings of World Geothermal Congress, New York, NY, 2000.

[7] M. S. Abfertiawan, R. S. Gautama, S. B. Kusuma, and S. Notosistima, "Hydrology simulation of Kud River in Lati Coal Mine," Journal of Novel Carbon Resource Sciences \& Green Asia Strategy, vol. 3, no. 01, pp. 21-31, 2016. doi: https: //doi.org/10.5109/1657737 
[8] R. Hall and M. Wilson, "Neogene sutures in Eastern Indonesia," Journal of Asian Earth Sciences, vol. 18, no. 6, pp. 781-808, 2000. doi: https://doi.org/10.1016/s1367-9120(00)00040-7

[9] E. Unal, I. T. Imer, E. Uysal, J. St Pierre, X. Zhao, and J. Shulmeister, "Last glacial climate oscillations and sudden environmental changes investigated in stalagmites from Southwest Sulawesi, Western Pacific," Turkish Journal of Earth Sciences, vol. 29, no. 2, pp. 221-241, 2020. doi: https://doi.org/10.3906/yer-1905-20

[10] S. M. Tim, "Laporan akhir survei magnetotelluric daerah panas bumi lili sepporak." [Online]. Available: https: //bit.ly/382aNRb

[11] S. Nadyrov, G. Geldyena, G. Nussupova, and A. Skakova, "Geographical aspects of organizing natural resource management structure in Kazakhstani section of a new economic zone of the silk road," International Journal of Applied and Physical Sciences, vol. 2, no. 3, pp. 59-64, 2016. doi: https://doi.org/10.20469/ijaps.2.50001-3

[12] N. D. K. Wicaksono, T. Winarno, and R. K. Ali, “Analisis karakteristik alterasi hidrotermal pada sumur ND-2 dan keterkaitannya dengan sumur ND-1 dalam permodelan sistem panasbumi daerah prospek panasbumi lilli-sepporaki, kabupaten polewali mandar, provinsi sulawesi barat," Ph.D. dissertation, Faculty of Engineeringn, Bandung Institute of Technology, Bandung, Indonesia, 2018.

[13] A. G. Jones and I. Dumas, "Electromagnetic images of a volcanic zone," Physics of the Earth and Planetary Interiors, vol. 81, no. 1-4, pp. 289-314, 1993. doi: https://doi.org/10.1016/0031-9201(93)90137-x

[14] G. A. Newman, E. Gasperikova, G. M. Hoversten, and P. E. Wannamaker, "Three-dimensional magnetotelluric characterization of the coso geothermal field," Geothermics, vol. 37, no. 4, pp. 369-399, 2008. doi: https://doi.org/10.1016/ j.geothermics.2008.02.006

[15] B. Steingrimsson, "Geothermal exploration and development from hot spring to utilization," in Proceedings of Short Course on Surface Exploration for Geothermal Resources, New York, NY, 2015.

[16] S. H. Tri Virgantoro, "Metode magnetotelluric untuk eksplorasi panasbumi daerah Lili,Sulawesi barat dengan data pendukung metode gravitasi," 2011. [Online]. Available: https://bit.ly/32AOMYw

[17] T. T. Survei, "Penyelidikian panas bumi terpadu geologi, geokimia dan geofisika daerah panas bumi polewali mandar, sulawesi barat," 2010. [Online]. Available: https://bit.ly/2Tmyyhx

[18] A. D. Chave and A. G. Jones, The Magnetotelluric Method: Theory and Practice. Cambridge, MA: Cambridge University Press, 2012.

[19] J. B. Wright, D. Hastings, W. Jones, and H. Williams, Geology and Mineral Resources of West Africa. New York, NY: Springer, 1985.

[20] M. Martinez-Garcia, "Electromagnetic induction in geothermal fields and volcanic belts," Surveys in Geophysics, vol. 13, no. 4-5, pp. 409-434, 1992. doi: https://doi.org/10.1007/bf01903485

[21] Y. Ogawa, N. Ujihara, S. B. Tank, Y. Honkura, S. Onizawa, T. Mori, M. Makino et al., 'Two electrical conductors beneath kusatsu-shirane volcano, Japan, imaged by audiomagnetotellurics, and their implications for the hydrothermal system," Earth, Planets and Space, vol. 58, no. 8, pp. 1053-1059, 2006. doi: https://doi.org/10.1186/bf03352610

[22] F. Simpson and K. Bahr, Practical Magnetotellurics. London, UK: Cambridge University Press, 2005.

[23] Geophysics for Practicing Geoscientists, "Electrical conductivity," 2019. [Online]. Available: https://bit.ly/2wMgqGf

[24] W. Zhu, C. David, and T.-f. Wong, "Network modeling of permeability evolution during cementation and hot isostatic pressing," Journal of Geophysical Research: Solid Earth, vol. 100, no. B8, pp. 15 451-15 464, 1995. doi: https://doi.org/ 10.1029/95jb00958

[25] G. D. Naidu, Deep Crustal Structure of the Son-Narmada-Tapti lineament. California, CA: Springer Science \& Business Media, 2012.

[26] Geo Data Solutions, “Airborn geophysics," 2018. [Online]. Available: https://bit.ly/3ceUNib 